Supporting Information

\title{
P-Type AsP Nanosheet as An Electron Donor for Stable Solar Broad-Spectrum Hydrogen Evolution
}

Cheng Lin, $\uparrow+$ Lianfu Jiang, $\uparrow+$ Dawei $\mathrm{Hu}, \uparrow$ Yiqun $\mathrm{Li}, \uparrow \mathrm{Bo} \mathrm{Cai}, \uparrow \mathrm{Jing} \mathrm{Li}, \uparrow \mathrm{Yu} \mathrm{Gu}, \uparrow$ Luyang Wang, $\S^{*}$ Kan Zhang, $\dagger^{*}$ Haibo Zeng $\dagger^{*}$

$\dagger$ Key Laboratory of Advanced Display Materials and Devices, Ministry of Industry and Information Technology, Institute of Optoelectronics \& Nanomaterials, College of Materials Science and Engineering, Nanjing University of Science and Technology, Nanjing 210094, China

$\S$ College of New Materials and New Energies, Shenzhen Technology University, Shenzhen, Guangdong 518118, China

*E-mail :

wangluyang@sztu.edu.cn

zhangkan@njust.edu.cn

zeng.haibo@njust.edu.cn 

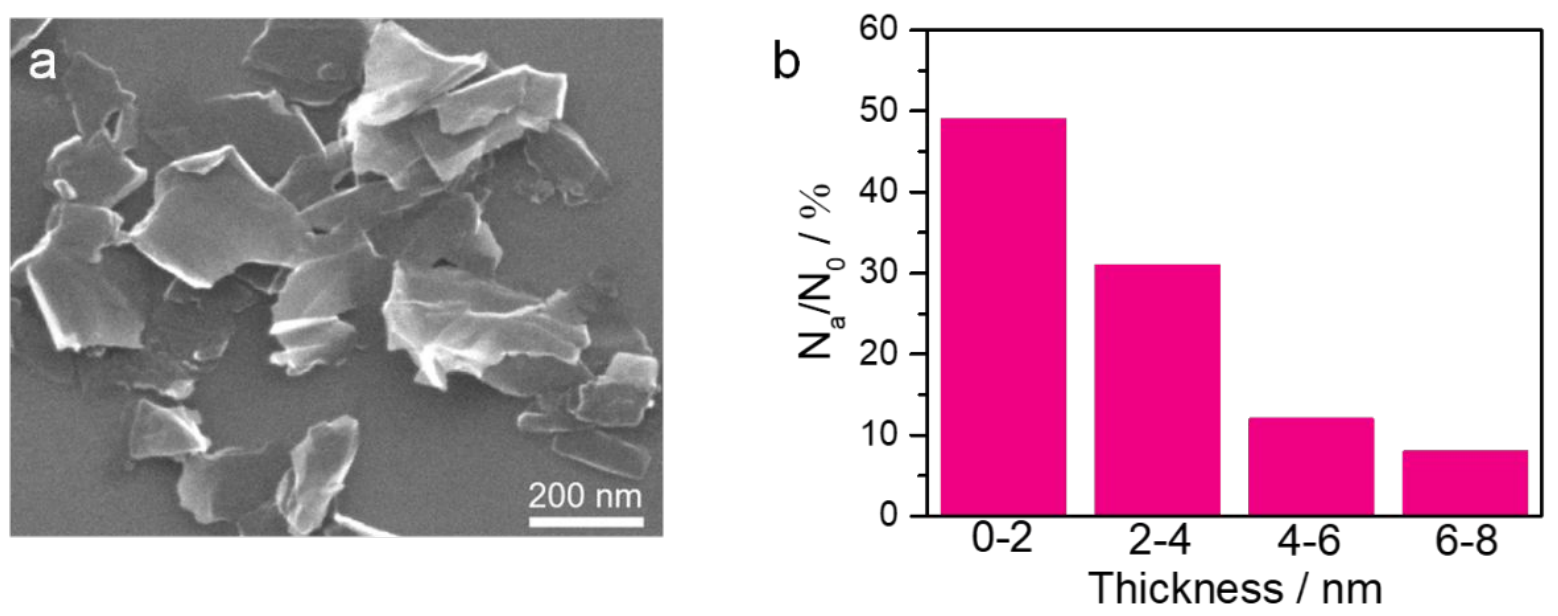

Figure S1. SEM image of exfoliated AsP NSs (a) and statistical histogram of the thickness on 100 AsP NSs (b). 


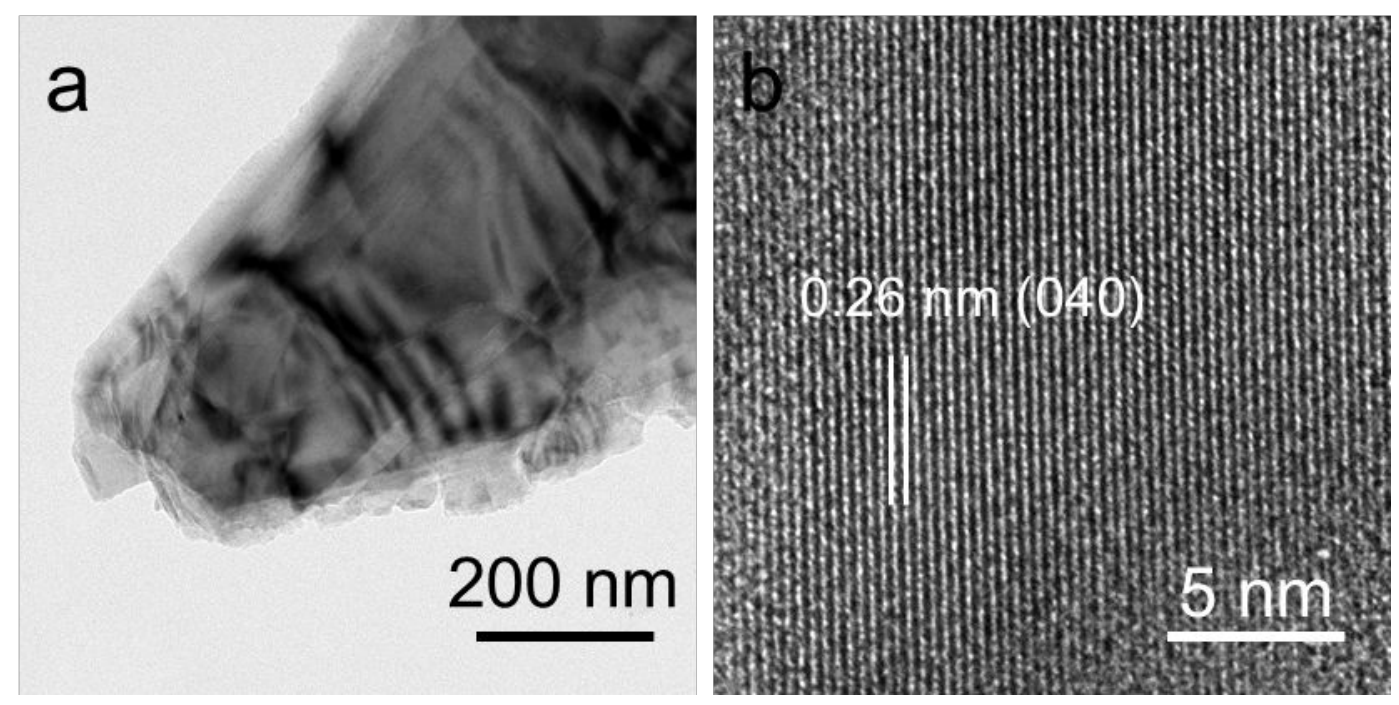

Figure S2. TEM (a) and HRTEM (b) graph of exfoliated BP NSs. 

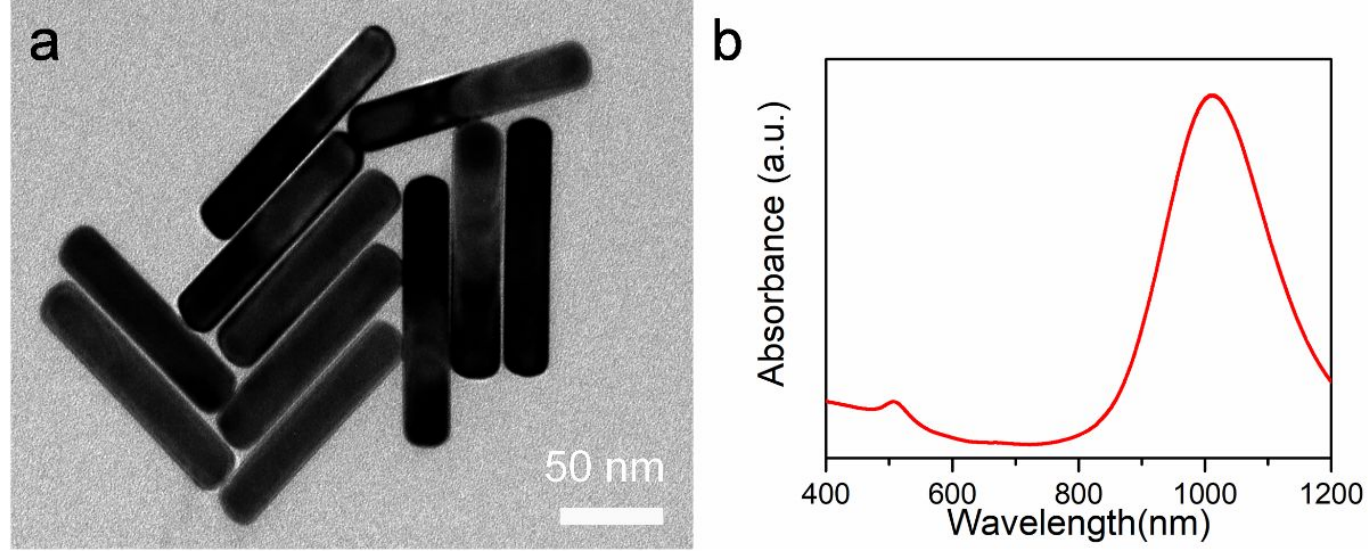

Figure S3. TEM image (a) and UV-vis-NIR absorption spectrum (b) of Au NRs. 

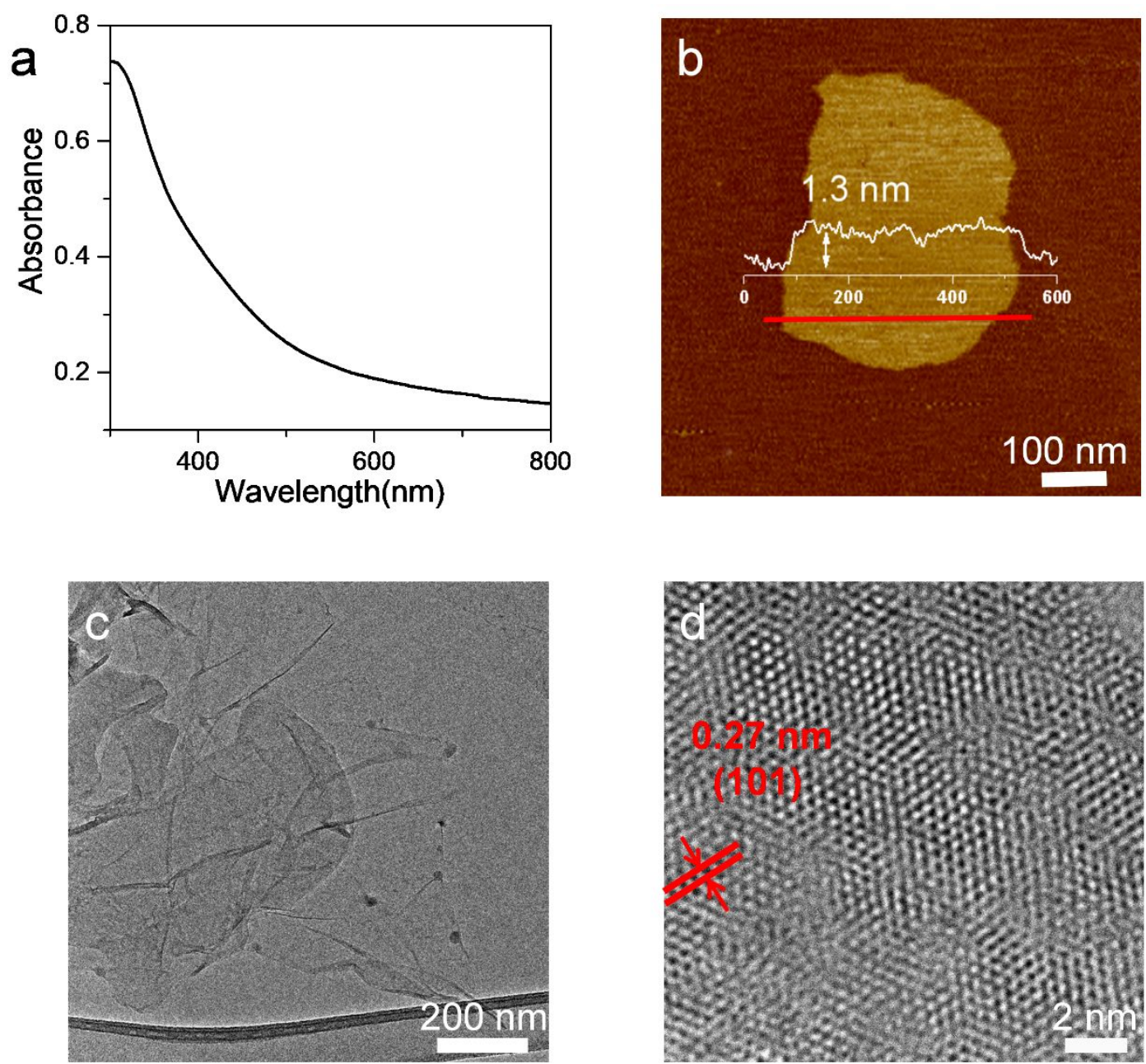

Figure S4. UV-vis absorption spectrum (a), AFM image (b), TEM image (c) and HRTEM image (d) of exfoliated $\mathrm{MoS}_{2}$ NSs. 

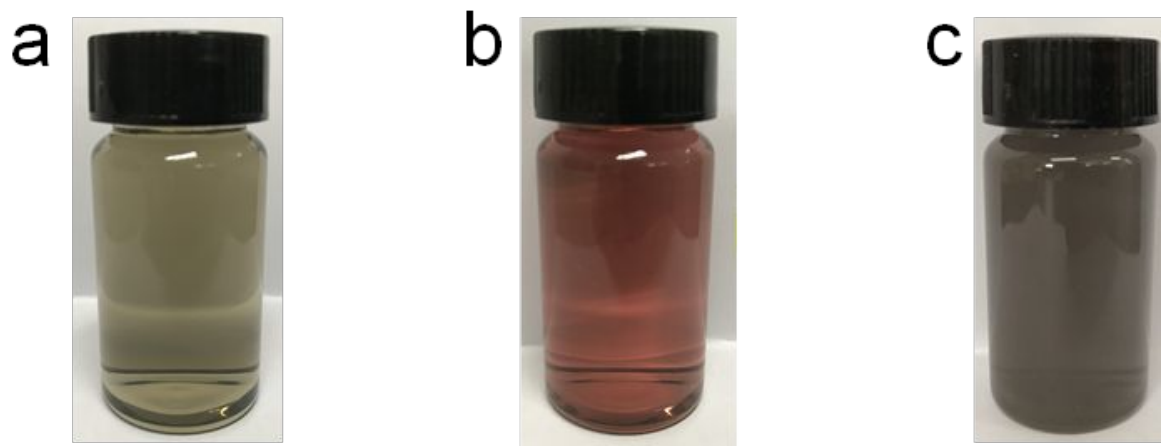

Figure S5. $\mathrm{MoS}_{2} \mathrm{NSs}(\mathrm{a})$, Au NRs (b) and AsP NSs (c) dispersed in water. 

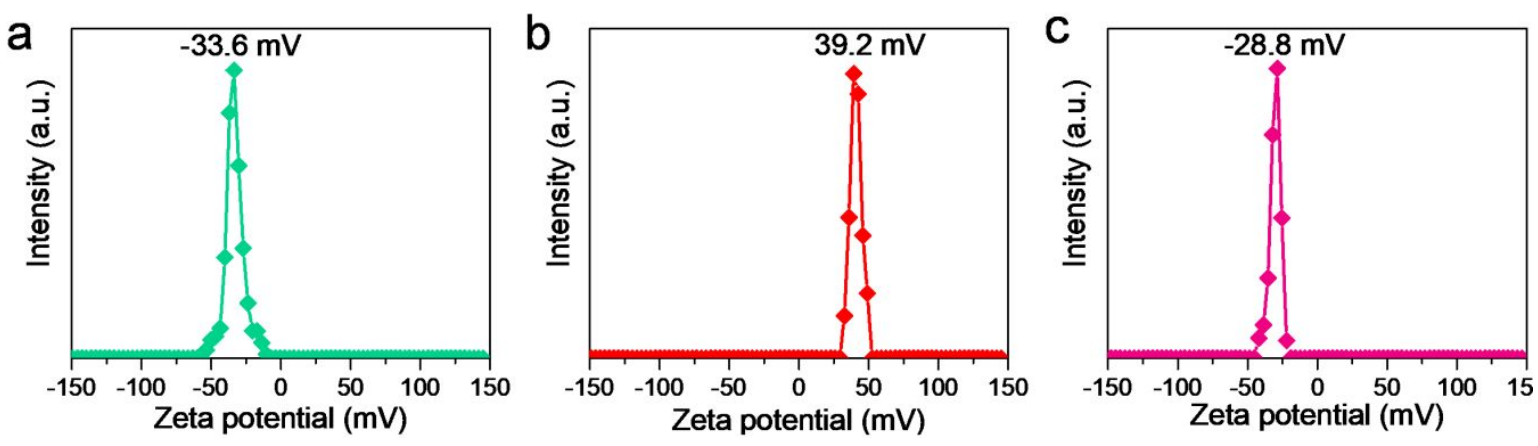

Figure S6. Zeta potential of AsP NSs (a), Au NRs (b) and $\mathrm{MoS}_{2} \mathrm{NSs}(\mathrm{c})$.

The assembly of $\mathrm{MoS}_{2}$ NSs and Au NRs was achieved through electrostatic interaction. Specifically, the insertion of each lithium-ion involves the injection of an electron into the $\mathrm{MoS}_{2}$ crystal in the process of lithium intercalation, while the insertion of considerable lithium ions will inject a massive electron into $\mathrm{MoS}_{2} \mathrm{NSs}$ which induces a phase transition of $\mathrm{MoS}_{2}$ from the semiconducting $2 \mathrm{H}$ phase to the metallic 1T phase. ${ }^{[1]}$ Consequently, $\mathrm{MoS}_{2}$ NSs were negatively charged. On the other hand, Au NRs were negatively charged due to the adsorption of chloride or bromides on the surface during the synthesis process. Thus, the positively charged ammonium head group of CTAB was bonded tightly to the Au NR through electrostatic interaction. Nevertheless, the carbon-chain tail at the other end of CTAB does not tend to stay in water owing to its hydrophobicity. Accordingly, the hydrophobic carbon-chain tail of the other layer of CTAB pointed to the inside which interacted with those of the inner layer, with the ammonium group pointing outside. Eventually, the CTAB bilayer made Au NRs positively charged. ${ }^{[2]}$ Therefore, positively charged Au NRs were uniformly bonded to the surface of the $\mathrm{MoS}_{2}$ NSs. The negative charge of AsP came from slight degradation products in the colloidal solution. Negatively charged AsP NSs tend to be combined with positively charged $\mathrm{Au}$ NRs. In summary, these three components can be selfassembled by electrostatic interaction. 

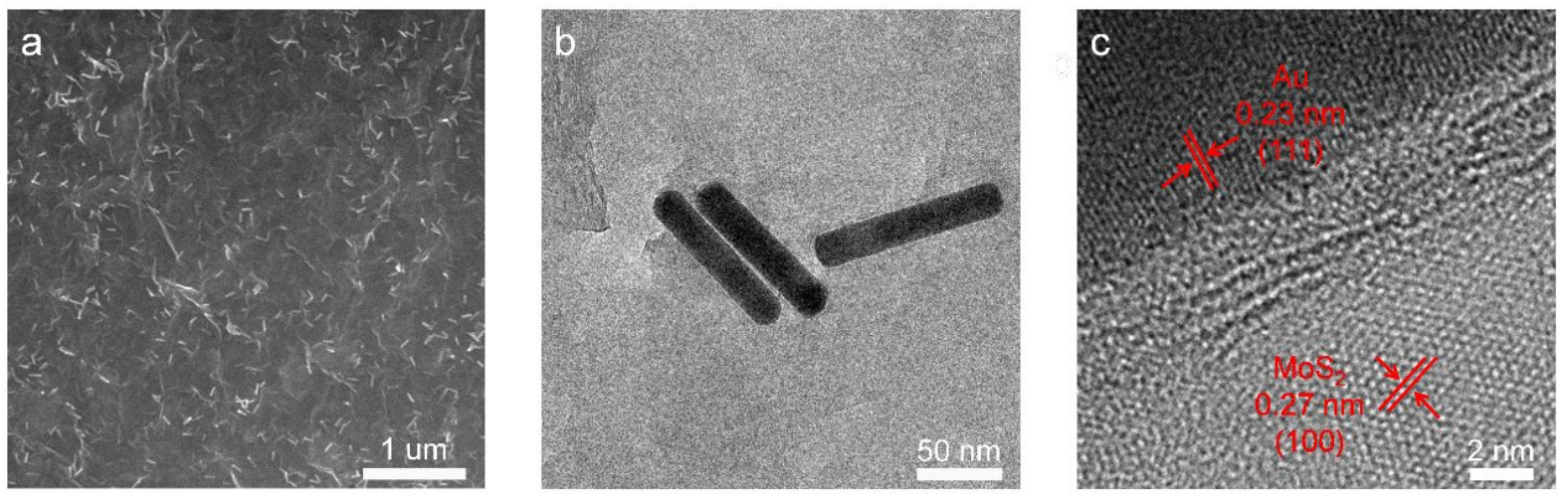

Figure S7. SEM (a), TEM (b) and HRTEM (c) of $\mathrm{MoS}_{2}$-Au binary heterojunction. 


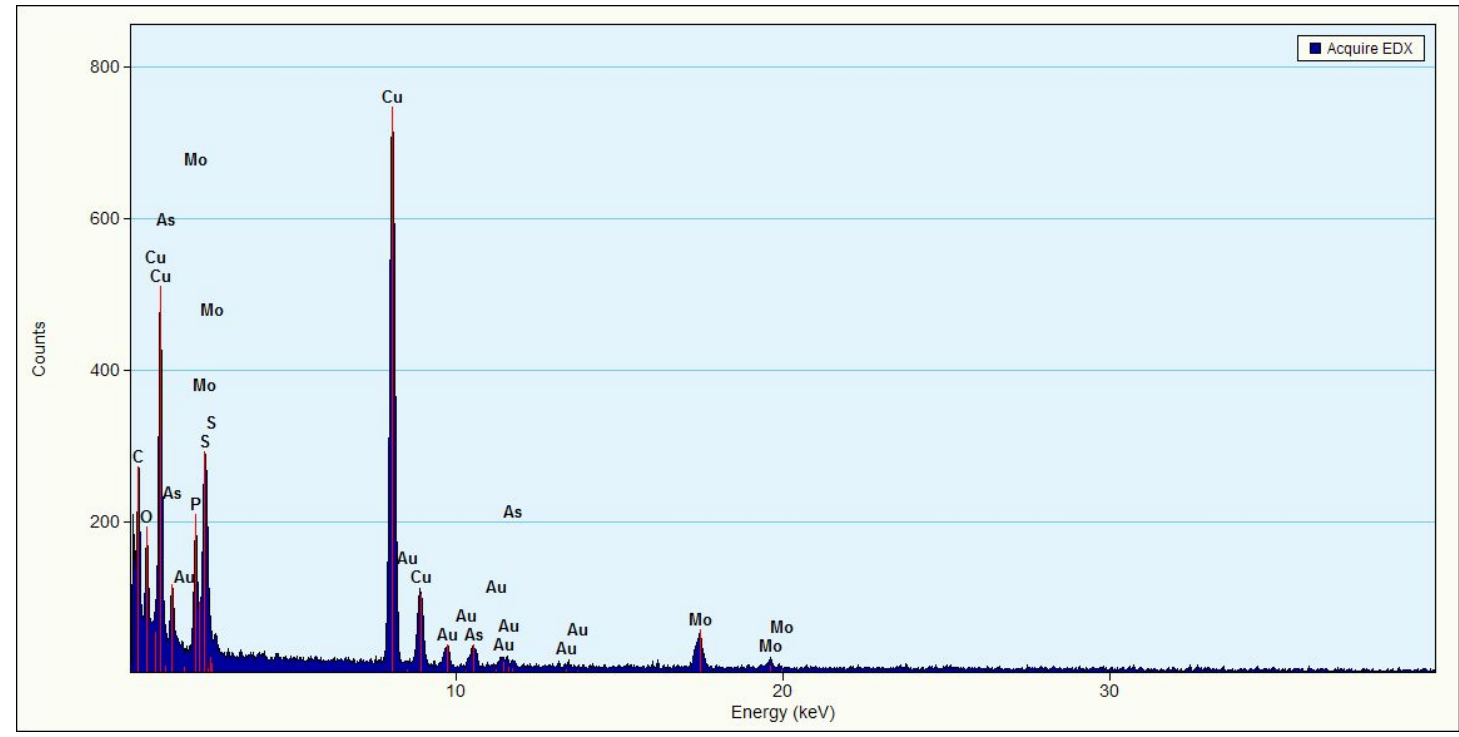

Figure S8. EDX spectrum of $\mathrm{MoS}_{2}$-Au-AsP ternary heterojunction from the area of TEM in Figure 2d. The peaks assigned to $\mathrm{Cu}$ and $\mathrm{C}$ signals were coming from the substrate for supporting samples. 


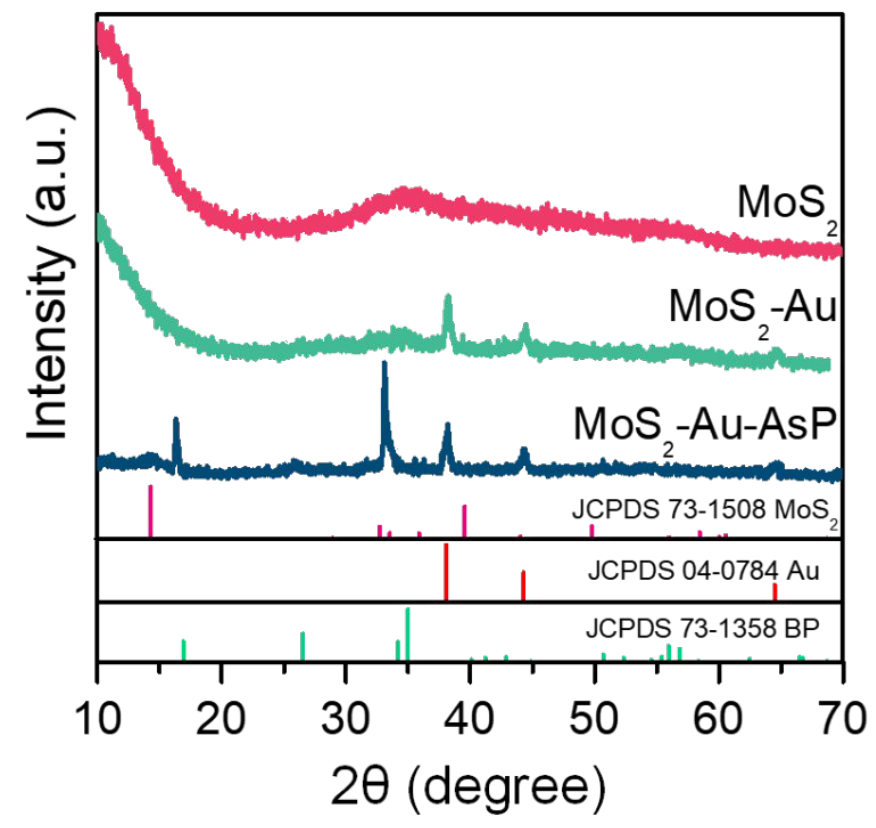

Figure S9. XRD patterns of $\mathrm{MoS}_{2}, \mathrm{MoS}_{2}-\mathrm{Au}$ and $\mathrm{MoS}_{2}-\mathrm{Au}-\mathrm{AsP}$ samples.

Phase composition analysis of the as-synthesized $\mathrm{MoS}_{2}, \mathrm{MoS}_{2}-\mathrm{Au}$, and $\mathrm{MoS}_{2}-\mathrm{Au}-\mathrm{AsP}$ samples was investigated by XRD. The pure $\mathrm{MoS}_{2}$ samples do not exhibit a diffraction peak (002) at around $14.4^{\circ}$, which usually appear in the bulk $\mathrm{MoS}_{2}$, suggesting successful exfoliation of a single or few layers of $\mathrm{MoS}_{2} \mathrm{NSs}^{[3]}$ In addition, a slight deviation can be found in the diffraction peaks of AsP compared to that of pure BP, which is ascribed to the substitution of As in the lattice of BP. ${ }^{[4]}$ 

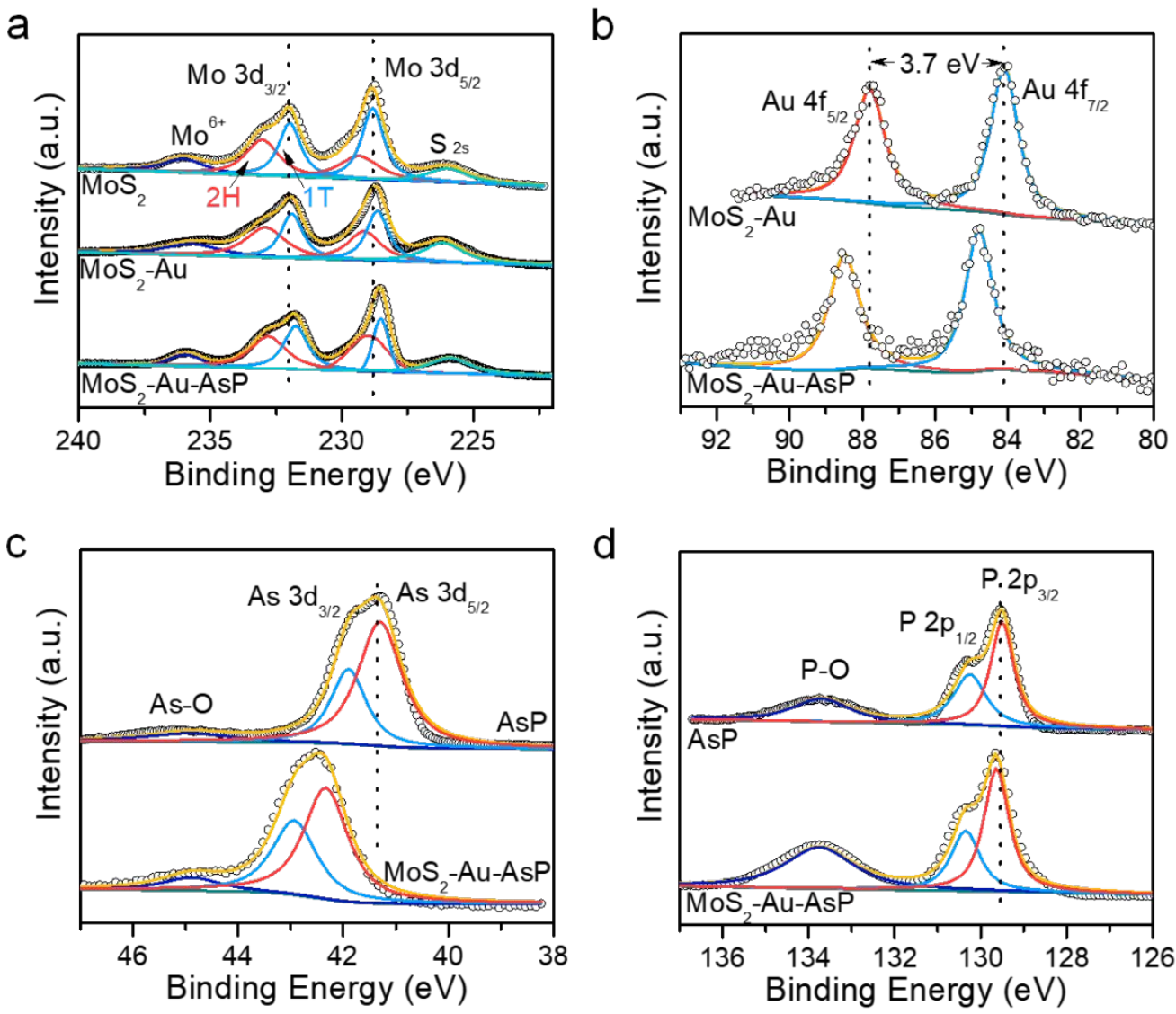

Figure S10. High-resolution XPS spectra of Mo 3d (a), Au 4f (b), As 3d (c), P 2p (d) of $\mathrm{MoS}_{2}, \mathrm{MoS}_{2}$-Au and $\mathrm{MoS}_{2}-\mathrm{Au}-\mathrm{AsP}$ samples.

It can be seen that the Mo 3d spectra of XPS consist of peaks at around $229.4 \mathrm{eV}$ and $233.0 \mathrm{eV}$ corresponding to $\mathrm{Mo}^{4+} 3 \mathrm{~d}_{5 / 2}$ and $\mathrm{Mo}^{4+} 3 \mathrm{~d}_{3 / 2}$ components of $2 \mathrm{H}-\mathrm{MoS}_{2}$, respectively (Figure S10a). Resulting from phase transition of $\mathrm{MoS}_{2}$ caused by lithium intercalation, deconvolution of the known peaks exhibit additional peaks that are shifted to lower binding energies by about $0.5 \mathrm{eV}$ and $1.0 \mathrm{eV}$ with regard to positions of the $1 \mathrm{~T}-\mathrm{MoS}_{2}$ peaks, respectively. ${ }^{[5]}$ The presence of the $\mathrm{Mo}^{6+}$ peak is attributed to air oxidation of the sample surface. In respect of $\mathrm{Au} 4 \mathrm{f}$ spectra in $\mathrm{MoS}_{2}$-Au composites (Figure S10b), the difference of $3.7 \mathrm{eV}$ between $\mathrm{Au} 4 \mathrm{f}_{7 / 2}(84.1 \mathrm{eV})$ and $\mathrm{Au} 4 \mathrm{f}_{5 / 2}(87.8$ $\mathrm{eV}$ ) indicates the formation of metallic $\mathrm{Au} .{ }^{[6]}$ As $3 \mathrm{~d}$ peaks (located at ca. 42.1 and 41.5 eV assigning to As $3 d_{3 / 2}$ and As $3 p_{5 / 2}$ ) and P 2p peaks (located at ca. 129.8 and 130.5 $\mathrm{eV}$ assigning to $\mathrm{P} 2 \mathrm{p}_{3 / 2}$ and $\mathrm{P} 2 \mathrm{p}_{1 / 2}$ ) are shown in XPS spectra (Figure S10c and $\mathrm{d}$ ). 
Additionally, oxidized phosphorus (P-O) and oxidized arsenic (As-O) bonds contribute from the slightly oxidized surface of AsP NSs during and after the exfoliation process. ${ }^{[7]}$ Given that the change of the binding energies can reveal the gain and loss of electrons, we can initially determine the direction of electron flow in the system. The XPS characterization reveals that the binding energies of Mo $3 \mathrm{~d}$ in $\mathrm{MoS}_{2}-\mathrm{Au}$ samples are negatively shifted, which indicates that electrons transfer from $\mathrm{Au}$ to $\mathrm{MoS}_{2}$. Furthermore, positive shifts of As 3d and P 2p XPS peaks imply that electrons in AsP prefer to flow to Au. More importantly, the further positive shift of Mo 3d XPS peaks demonstrates that the unidirectional electron flow from $\mathrm{AsP}$ to $\mathrm{Au}$ and then to $\mathrm{MoS}_{2}$ is realized in the system. 

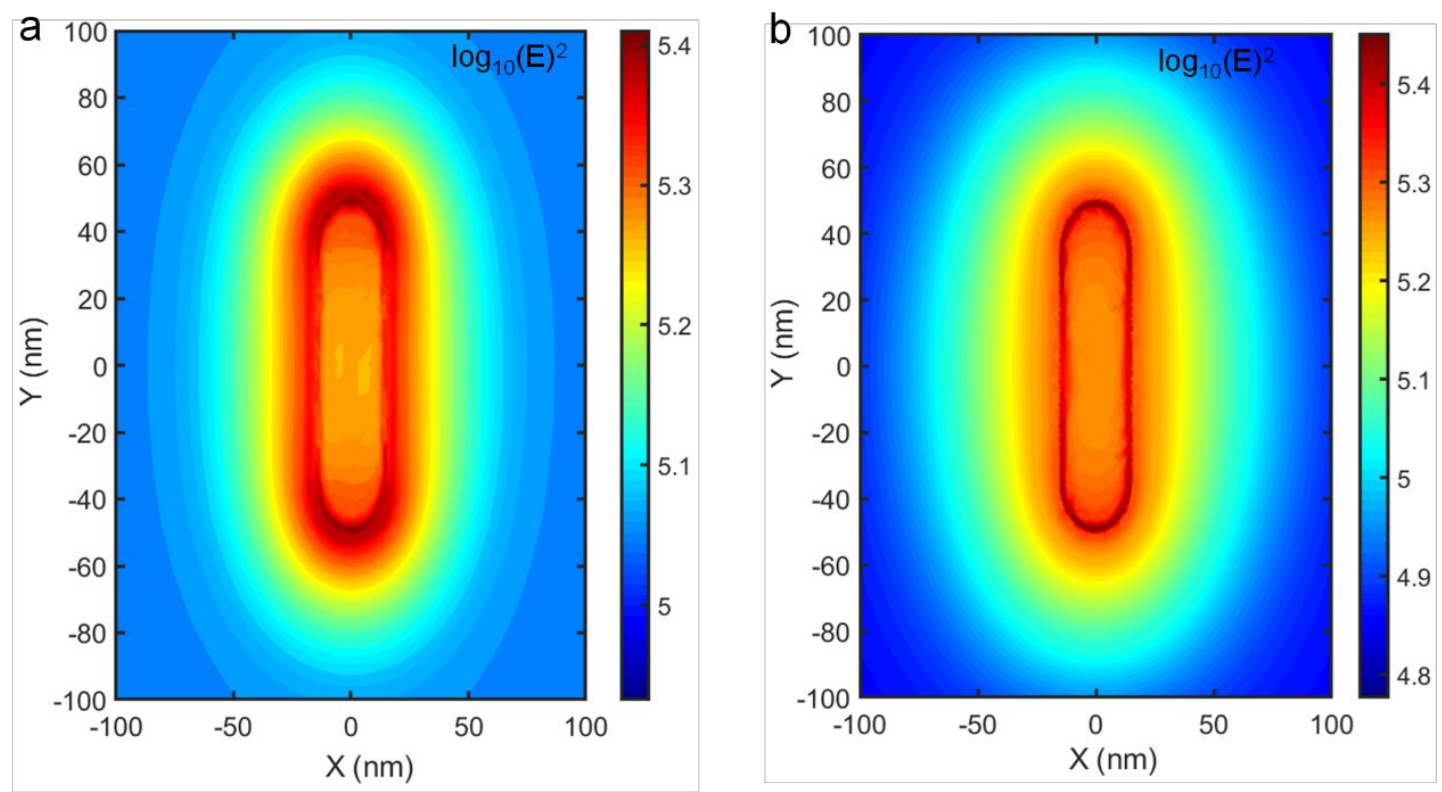

Figure S11. The finite element simulation of the near-field distribution of AsP NSs (a) and $\mathrm{MoS}_{2}$ NSs (b) NSs under $507 \mathrm{~nm}$ irradiation. 

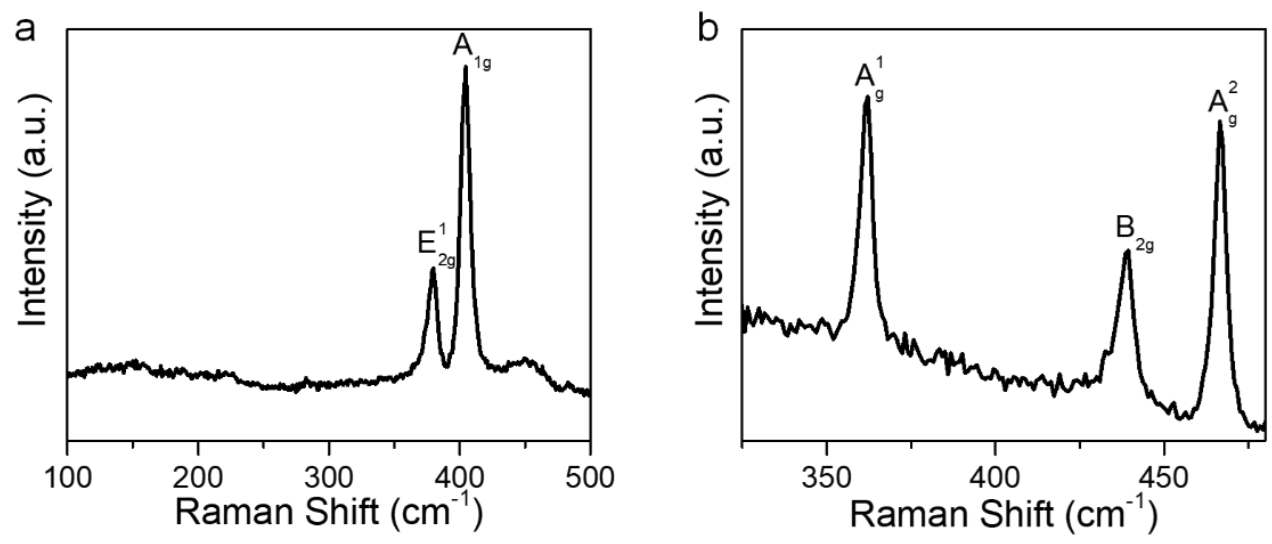

Figure S12. Raman spectrum of bulk $\mathrm{MoS}_{2}$ (a) and pristine BP (b).

Only in-plane $\mathrm{E}_{2 \mathrm{~g}}$ and out-of-plane $\mathrm{A}_{1 \mathrm{~g}}$ mode can be seen in bulk $2 \mathrm{H}-\mathrm{MoS}_{2}$ (Figure S12a).

As shown in Figure S12b, there are three peaks at $362.0 \mathrm{~cm}^{-1}, 438.9 \mathrm{~cm}^{-1}, 466.6 \mathrm{~cm}^{-1}$ which can be detected from pristine BP NSs corresponding to an out-of-plane vibrational mode of $\mathrm{A}_{\mathrm{g}}^{1}$, two in-plane vibrational modes of $\mathrm{B}_{2 \mathrm{~g}}$ and $\mathrm{A}_{\mathrm{g}}{ }^{2} \cdot{ }^{[7 \mathrm{a}]}$ 

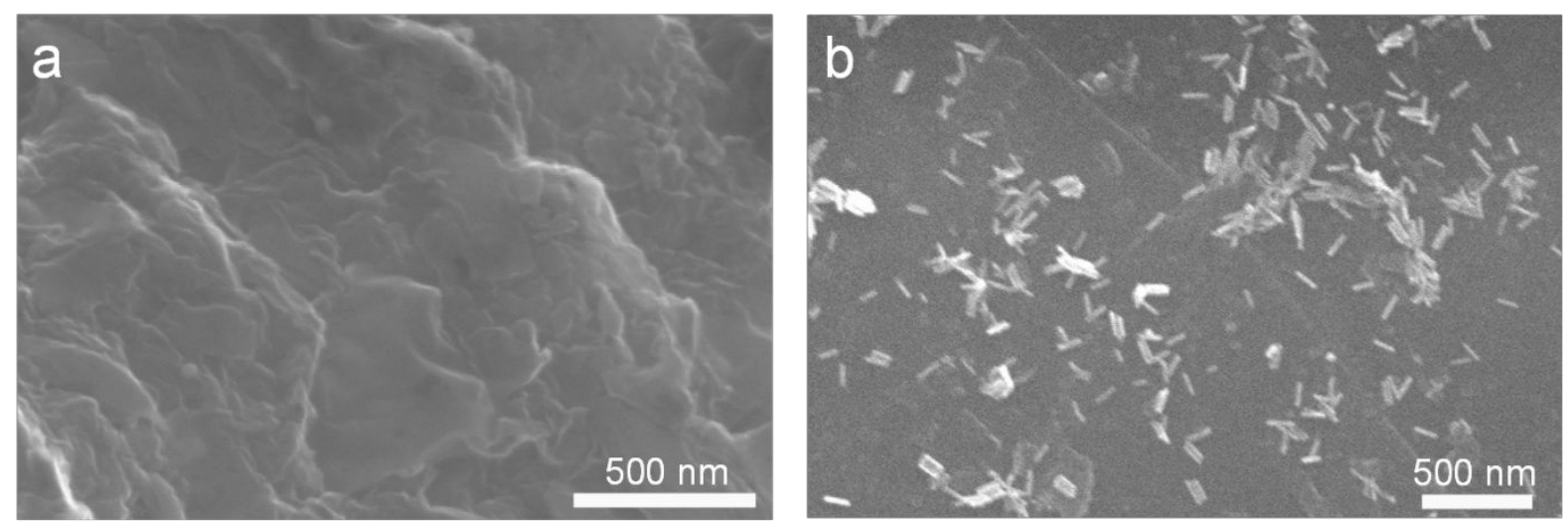

Figure S13. SEM images of $\mathrm{MoS}_{2}-\mathrm{AsP}(\mathrm{a})$ and $\mathrm{AsP}-\mathrm{Au}(\mathrm{b})$ binary heterojunction. 

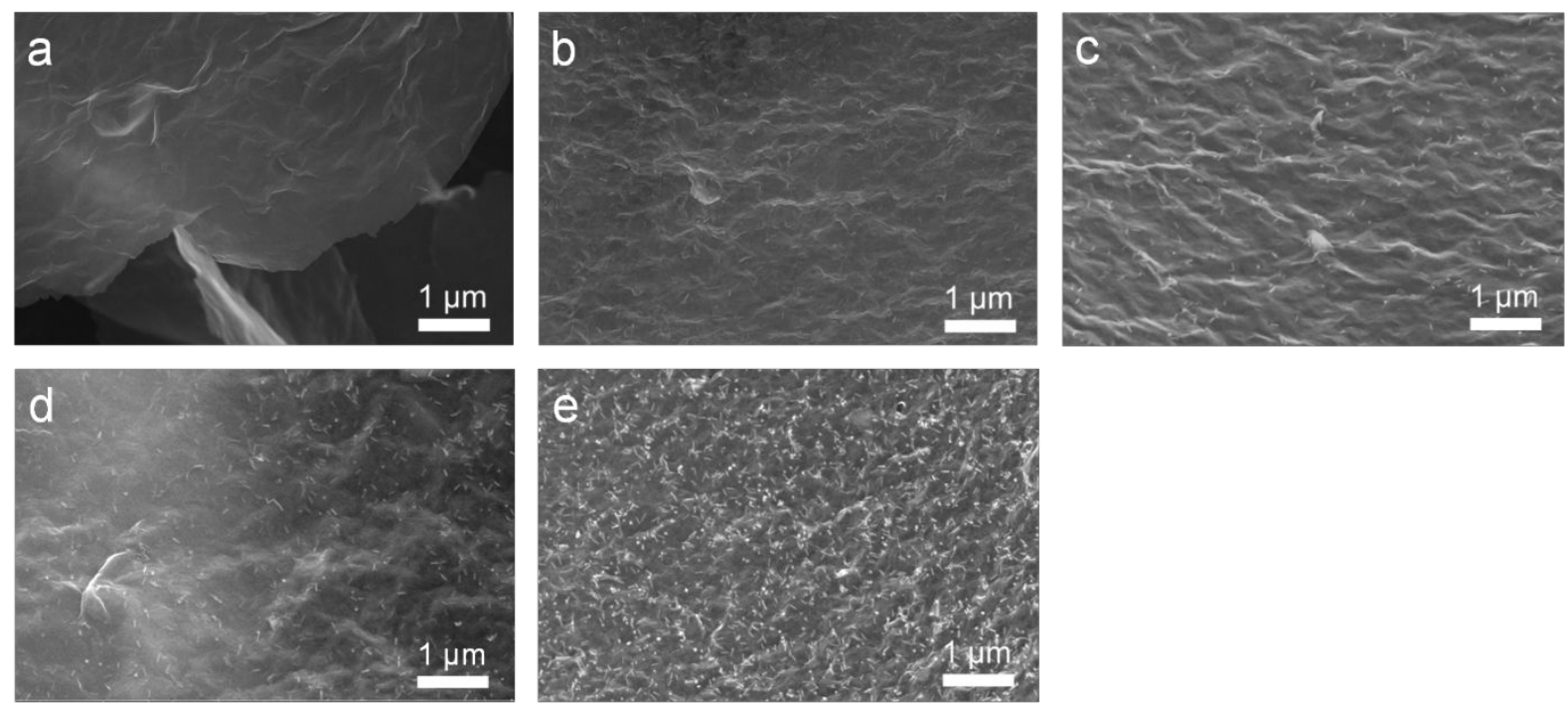

Figure S14. SEM images of $\mathrm{MoS}_{2}$-Au binary heterojunction with different weights of Au: 0 wt\% (a), 3.09 wt\% (b), $6.18 \mathrm{wt} \%$ (c), $9.26 \mathrm{wt} \%$ (d) and $12.35 \mathrm{wt} \%$ (e). 

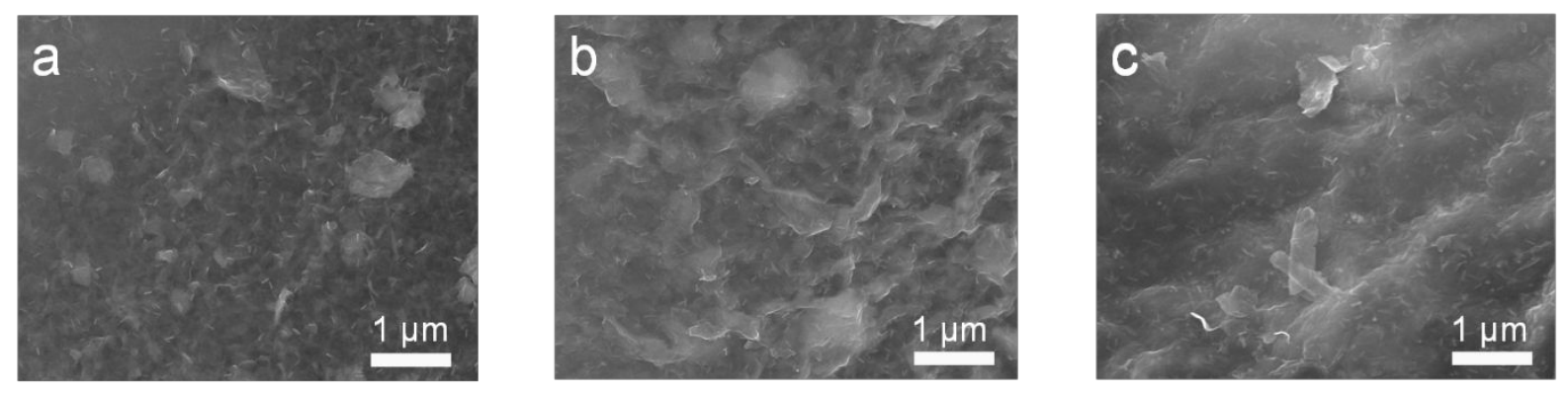

Figure S15. SEM images of $\mathrm{MoS}_{2}$-Au-AsP ternary heterojunction with different weights of AsP: $15 \mathrm{wt} \%$ (a), $30 \mathrm{wt} \%$ (b) and $60 \mathrm{wt} \%$ (c). 

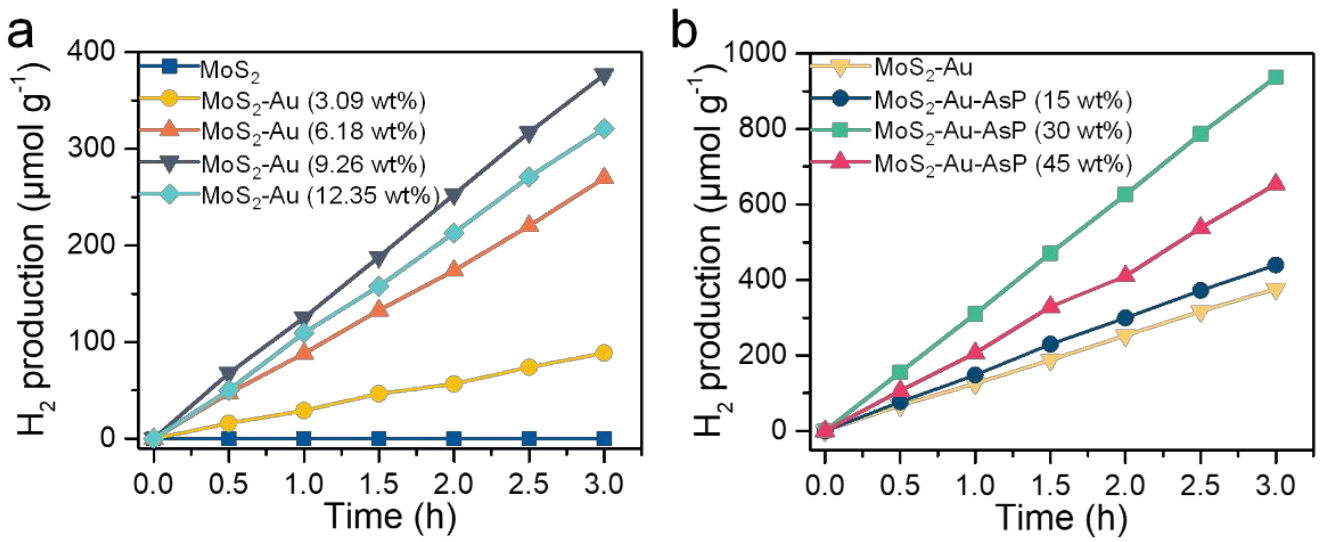

Figure S16. Photocatalytic hydrogen generation performance of $\mathrm{MoS}_{2}$-Au binary heterojunction with different weights of $\mathrm{Au}$ (a) and $\mathrm{MoS}_{2}$-Au-AsP ternary heterojunction with different weights of AsP (b). 

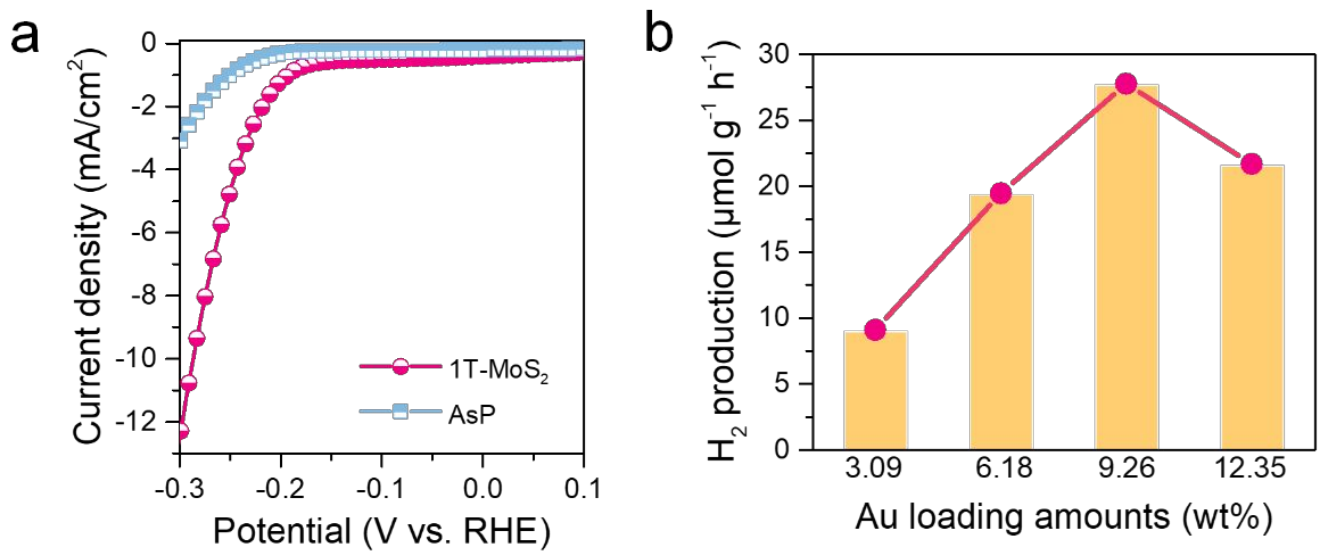

Figure S17. Polarization curves of $\mathrm{MoS}_{2}$ and AsP (a). Photocatalytic hydrogen generation performance of $\mathrm{AsP}-\mathrm{Au}$ binary heterojunction with different weights of $\mathrm{Au}$ (b).

As shown in Figure S17a, The polarization curves of as-synthesized $\mathrm{MoS}_{2}$ and AsP NSs exhibit their own electrocatalytic HER performance. Compared to AsP NSs, 1T-MoS 2 NSs in our case were characterized by a lower overpotential and revealed a higher current density.

As shown in Figure S17b, AsP with 9.26\% Au loading presents optimal $\mathrm{H}_{2}$ production activity $\left(27.65 \mu \mathrm{molg}^{-1} \mathrm{~h}^{-1}\right)$, which is inferior to $\mathrm{MoS}_{2}$-Au binary heterojunction (125.54 $\mu$ molg $\left.^{-1} h^{-1}\right)$. In addition, the $\mathrm{H}_{2}$ production rate of AsP-Au is improved by a combination of $\operatorname{MoS}_{2}\left(314.61 \mu \mathrm{molg}^{-1} \mathrm{~h}^{-1}\right)$.

The results confirm that exfoliated $1 \mathrm{~T}-\mathrm{MoS}_{2} \mathrm{NSs}$ are promising catalysts for HER indeed and the role of $\mathrm{MoS}_{2}$ as hydrogenase in PS I . 

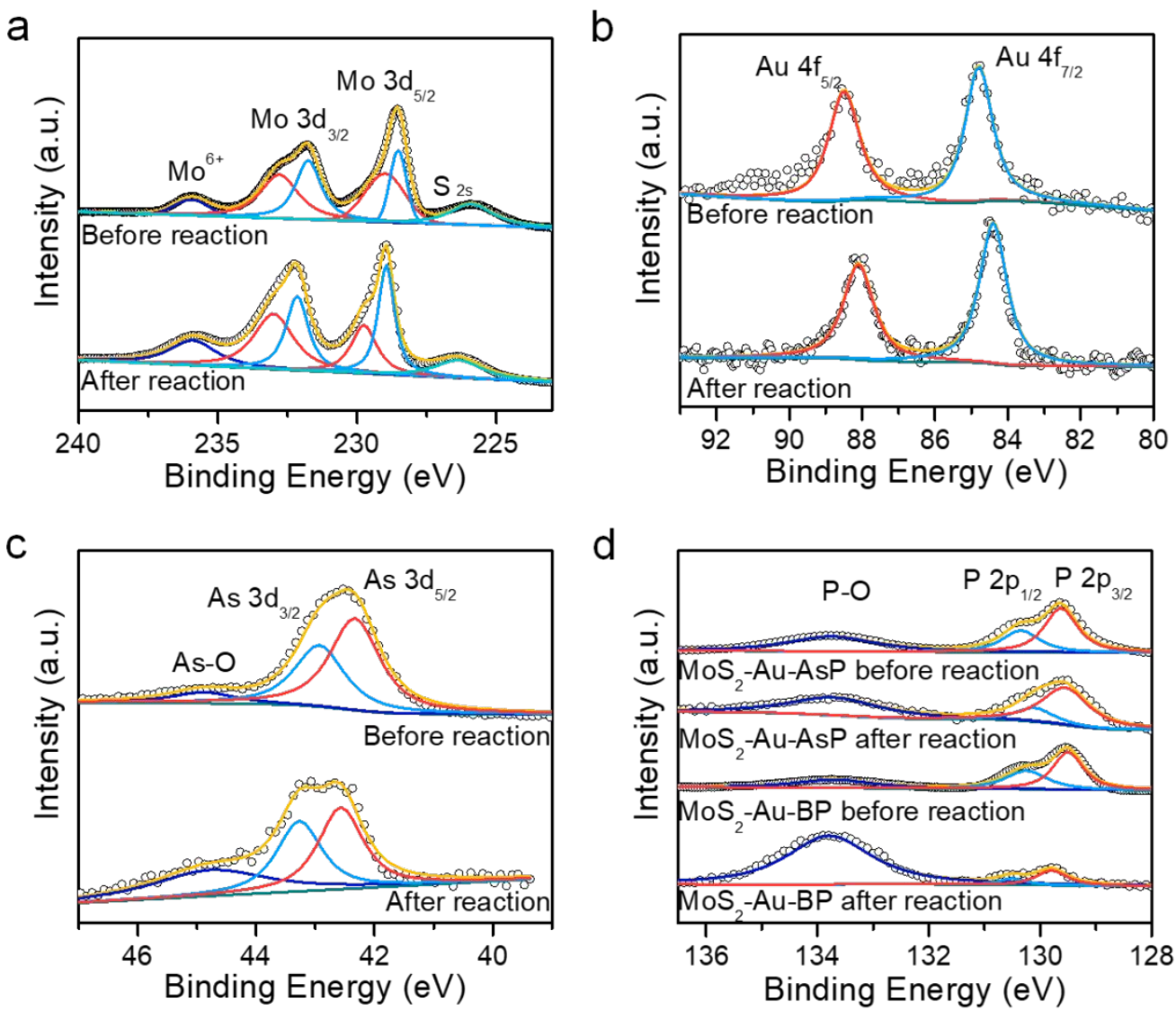

Figure S18. High-resolution XPS spectra of Mo 3d (a), Au 4f (b), As 3d (c), of $\mathrm{MoS}_{2}-$ $\mathrm{Au}$-AsP ternary heterojunction before and after the photocatalytic reaction. Highresolution XPS spectra of $\mathrm{P} 2 \mathrm{p}$ of MoS2-Au-AsP and MoS2-Au-BP ternary heterojunction before and after photocatalytic reaction (d). 

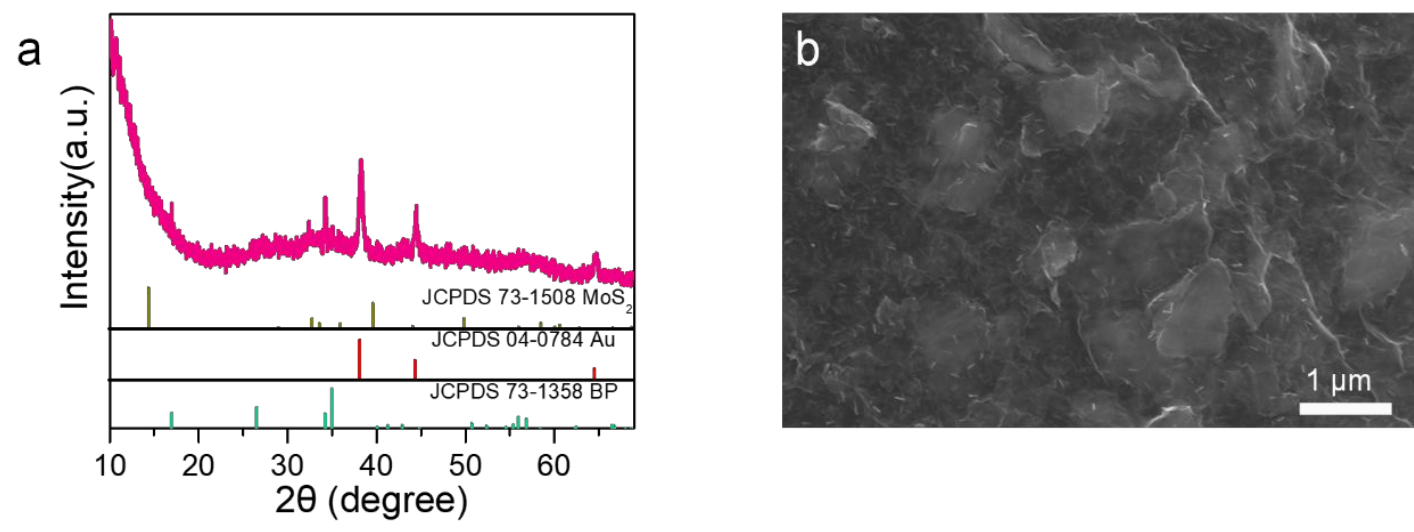

Figure S19. XRD patterns (a) and SEM graph (b) of $\mathrm{MoS}_{2}-\mathrm{Au}-\mathrm{BP}$ ternary heterojunction. 


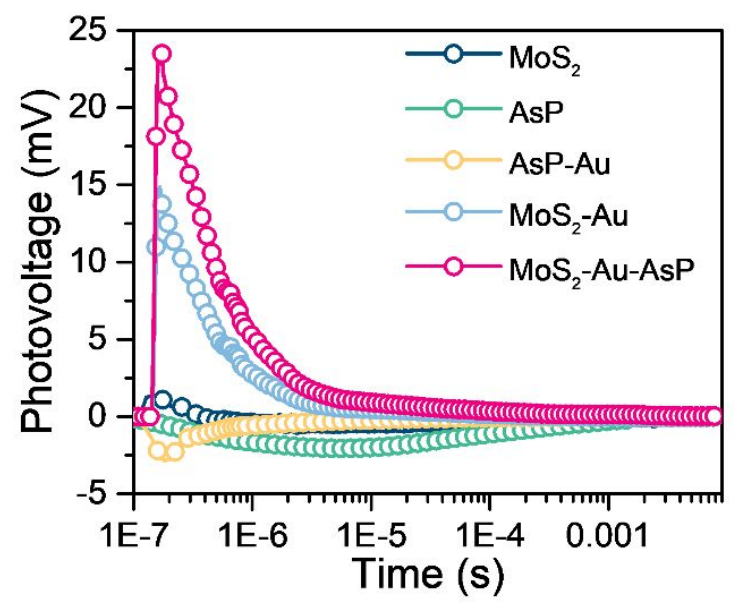

Figure S20. TPV measurements of different samples under $355 \mathrm{~nm}$ laser irradiation.

Under $355 \mathrm{~nm}$ irradiation, pure $\mathrm{MoS}_{2}$ generates a positive photovoltage response, while a positive TPV signal has also been obtained for the $\mathrm{MoS}_{2}$-Au composites. When light illuminates the $\mathrm{MoS}_{2}$-Au composites, photoinduced holes in $\mathrm{MoS}_{2}$ would be transferred to $\mathrm{Au}$ densely distributed on the $\mathrm{MoS}_{2}$ through the barrier region produced by contact potential difference between $\mathrm{MoS}_{2}$ and $\mathrm{Au}$, bringing about the positive TPV response. Moreover, the photovoltage response intensity of $\mathrm{MoS}_{2}-\mathrm{Au}$ is much stronger than that of bare $\mathrm{MoS}_{2}$ due to the efficient interfacial charge transfer. Excited by $355 \mathrm{~nm}$ pulse laser, AsP exhibits the same negative transient signal as to when excited by $1064 \mathrm{~nm}$ laser. What's more, when Au NRs are loaded on the surface of the AsP NSs, only AsP would be excited under $355 \mathrm{~nm}$ irradiation. The ultimate negative photovoltage transient response suggested that the photogenerated electrons produced from AsP NSs are transferred to the surface of Au NRs through the interface. Hot electrons excited by $1064 \mathrm{~nm}$ in $\mathrm{Au}$ NRs can be injected into $\mathrm{MoS}_{2}$ by overcoming the Schottky barrier $(<$ $0.8 \mathrm{eV}$ ). Therefore, photo-induced electrons in AsP (bandgap: $0.88 \mathrm{eV}$ ) (Figure S20) also have sufficient energy to flow into $\mathrm{MoS}_{2}$. Under $355 \mathrm{~nm}$ irradiation, the unidirectional electron flow from AsP to $\mathrm{Au}$ and then to $\mathrm{MoS}_{2}$ in PS I can also be realized even though Au NRs do not generate SPR effect. 


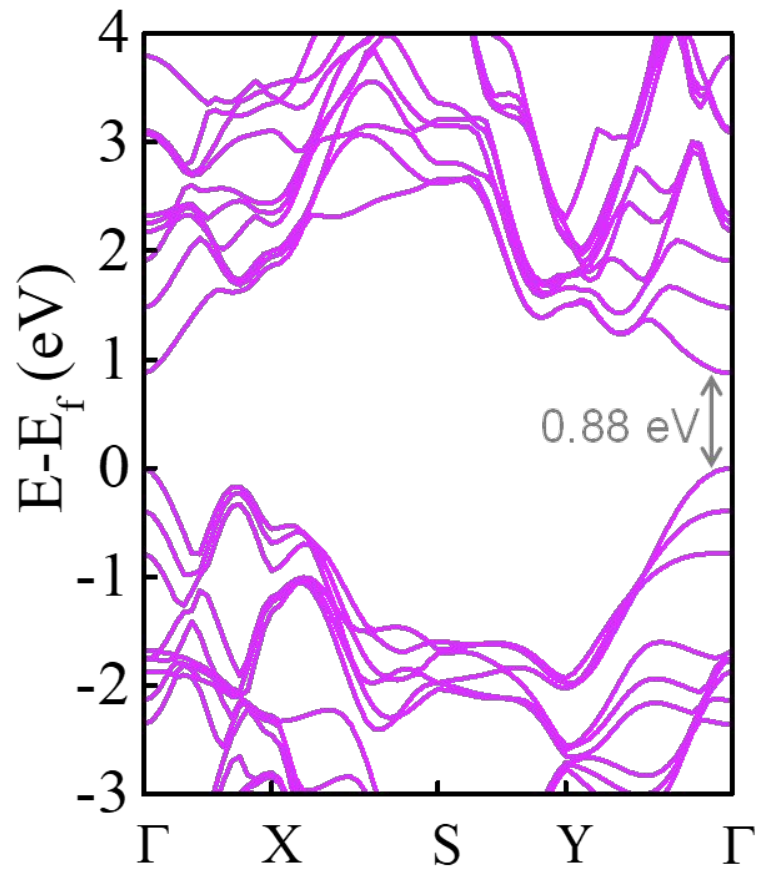

Figure S21. Schematic energy-level diagram of four-layer AsP. 
Table S1. Comparison of various BP-based photocatalysts for photocatalytic $\mathrm{H}_{2}$ generation.

\begin{tabular}{|c|c|c|c|c|c|c|}
\hline Photocatalysts & $\begin{array}{l}\text { Catalyst } \\
\text { dosage } \\
(\mathrm{mg})\end{array}$ & Reactant solution & Light source & Stability & $\begin{array}{c}\mathrm{H}_{2} \text { evolution rate } \\
\left(\mu \text { molg }^{-1} \mathrm{~h}^{-1}\right)\end{array}$ & References \\
\hline $\mathrm{MoS}_{2}-\mathrm{Au}-\mathrm{AsP}$ & 5 & $\begin{array}{c}10 \mathrm{vol} \% \\
\text { lactic acid } \\
\text { aqueous solution }\end{array}$ & $\begin{array}{c}300 \mathrm{~W} \text { Xe lamp } \\
(\lambda>700 \mathrm{~nm})\end{array}$ & $\begin{array}{l}3 \text { cycles for } 9 \mathrm{~h} \text {, } \\
\text { another } 3 \text { cycles } \\
\text { after stored } 6 \\
\text { months }\end{array}$ & 125.52 & This work \\
\hline $\begin{array}{c}\text { MPG-CN/BP- } \\
\mathrm{Au}\end{array}$ & 10 & $\begin{array}{l}10 \text { vol \% TEOA } \\
\text { aqueous solution }\end{array}$ & $\begin{array}{c}300 \mathrm{~W} \text { Xe lamp } \\
(\lambda>420 \mathrm{~nm})\end{array}$ & 3 cycles for $15 \mathrm{~h}$ & 128 & [8] \\
\hline $\mathrm{BP} / \mathrm{g}-\mathrm{C}_{3} \mathrm{~N}_{4}$ & 1.5 & $\begin{array}{l}20 \text { vol \% methanol } \\
\text { aqueous solution }\end{array}$ & $\begin{array}{c}\text { Xe lamp Asahi } \\
\text { Spectra } \\
\text { HAL-320W } \\
(\lambda>780 \mathrm{~nm})\end{array}$ & $\begin{array}{l}3 \text { cycles for } 15 \mathrm{~h} \text {, } \\
\text { another } 1 \text { cycle } \\
\text { after stored } 2 \\
\text { weeks }\end{array}$ & 101 & [9] \\
\hline $\mathrm{CdS} / \mathrm{BP}-\mathrm{MoS}_{2}$ & 1 & $\begin{array}{l}20 \text { vol \% lactic } \\
\text { acid solution }\end{array}$ & $\begin{array}{c}150 \text { W Xe lamp } \\
(\lambda>700 \mathrm{~nm})\end{array}$ & 6 cycles for $6 \mathrm{~h}$ & Ca. 50 & [10] \\
\hline $\mathrm{BP} / \mathrm{Pt} / \mathrm{RGO}$ & 0.2 & $\begin{array}{l}\text { EDTA solution }(0.5 \\
\qquad \mathrm{M})\end{array}$ & $\begin{array}{c}\text { Xe lamp Asahi } \\
\text { Spectra } \\
\text { HAL-320W } \\
(\lambda>780 \mathrm{~nm})\end{array}$ & 5 cycles for $20 \mathrm{~h}$ & 62 & [11] \\
\hline BP-BM/WN & 10 & Deionized water & $\begin{array}{c}\text { Xe lamp Asahi } \\
\text { Spectra } \\
\text { HAL-320W } \\
(\lambda>700 \mathrm{~nm})\end{array}$ & $\begin{array}{l}3 \text { cycles for } 15 \mathrm{~h} \text {, } \\
\text { another } 2 \text { cycles } \\
\text { after stored } \\
\text { 1month }\end{array}$ & 10.77 & [12] \\
\hline $\mathrm{Co}_{2} \mathrm{P} / \mathrm{BP}$ & 10 & $\begin{array}{c}0.1 \mathrm{M} \mathrm{Na}_{2} \mathrm{~S} \text { and } 0.1 \mathrm{M} \\
\qquad \mathrm{Na}_{2} \mathrm{SO}_{3} \\
\text { aqueous solution }\end{array}$ & $\begin{array}{c}300 \text { W Xe lamp } \\
(\lambda>550 \mathrm{~nm})\end{array}$ & 3 cycles for $12 \mathrm{~h}$ & 202 & [13] \\
\hline
\end{tabular}




\begin{tabular}{|c|c|c|c|c|c|c|}
\hline BPQD- $\mathrm{C}_{3} \mathrm{~N}_{4}$ & 100 & $\begin{array}{l}10 \mathrm{vol} \% \text { methanol } \\
\text { aqueous solution }\end{array}$ & $\begin{array}{c}200 \text { W Xe lamp } \\
\text { (simulated } \\
\text { sunlight) }\end{array}$ & 5 cycles for $25 \mathrm{~h}$ & 1.9 & [14] \\
\hline BP NS/TMC & 2 & $\begin{array}{l}20 \mathrm{vol} \% \text { methanol } \\
\text { aqueous solution }\end{array}$ & $\begin{array}{c}\text { Xe lamp Asahi } \\
\text { Spectra } \\
\text { HAL-320W } \\
(\lambda>780 \mathrm{~nm})\end{array}$ & $\begin{array}{c}4 \text { cycles for } 800 \\
\min \end{array}$ & 200 & [15] \\
\hline BP-Au/LTO & 1.5 & $\begin{array}{c}20 \mathrm{vol} \% \text { methanol } \\
\text { aqueous solution }\end{array}$ & $\begin{array}{c}\text { Xe lamp Asahi } \\
\text { Spectra } \\
\text { HAL-320W } \\
(\lambda>780 \mathrm{~nm})\end{array}$ & 4 cycles for $12 \mathrm{~h}$ & 293 & {$[16]$} \\
\hline
\end{tabular}


Table S2. Summary of PL lifetimes and fractional intensities of AsP, AsP-Au and $\mathrm{MoS}_{2}$-Au-AsP samples from $500 \mathrm{~nm}$ excitation at $80 \mathrm{~K}$. PL decay curves were fitted according to the bi-exponential function: $\gamma=A_{1} e^{\frac{-x}{\tau_{1}}}+A_{2} e^{\frac{-x}{\tau_{2}}}+\gamma_{0}$, by which the sample lifetimes can be calculated. The intensity-weighted average exciton lifetime $\left(\tau_{\text {avr }}\right)$ was $A_{1} \tau_{1}+A_{2} \tau_{2}$, where $A_{1}$ and $A_{2}$ are fractional intensities and $\tau_{1}$ and $\tau_{2}$ are lifetimes.

\begin{tabular}{cccccc}
\hline sample & $\mathbf{A}_{\mathbf{1}}(\boldsymbol{\%})$ & $\boldsymbol{\tau}_{\mathbf{1}}(\mathbf{n s})$ & $\mathbf{A}_{\mathbf{2}}(\boldsymbol{\%})$ & $\boldsymbol{\tau}_{\mathbf{2}}(\mathbf{n s})$ & $\boldsymbol{\tau}_{\text {avr }}(\mathbf{n s})$ \\
\hline AsP & 0.93 & 0.74 & 0.07 & 2.79 & 0.88 \\
AsP-Au & 0.94 & 0.76 & 0.06 & 3.17 & 0.90 \\
MoS $_{2}-\mathbf{A u}-\mathbf{A s P}$ & 0.98 & 0.86 & 0.02 & 7.35 & 0.99 \\
\hline
\end{tabular}




\section{References}

[1] Z. Lin, Y. Liu, U. Halim, M. Ding, Y. Liu, Y. Wang, C. Jia, P. Chen, X. Duan, C.

Wang, F. Song, M. Li, C. Wan, Y. Huang, X. Duan, Nature 2018, 562, 254.

[2] S. Gomez-Grana, F. Hubert, F. Testard, A. Guerrero-Martinez, I. Grillo, L. M.

Liz-Marzan, O. Spalla, Langmuir 2012, 28, 1453.

[3] G. Eda, H. Yamaguchi, D. Voiry, T. Fujita, M. Chen, M. Chhowalla, Nano Lett. 2011, 11, 5111 .

[4] Z. Zeng, Z. Yin, X. Huang, H. Li, Q. He, G. Lu, F. Boey, H. Zhang, Angew.

Chem. 2011, 50, 11093.

[5] O. Osters, T. Nilges, F. Bachhuber, F. Pielnhofer, R. Weihrich, M. Schoneich, P. Schmidt, Angew. Chem. 2012, 51, 2994.

[6] L. E. Davis, Physical Electronics Division 1978.

[7] a) X. Zhang, H. Xie, Z. Liu, C. Tan, Z. Luo, H. Li, J. Lin, L. Sun, W. Chen, Z. Xu, L. Xie, W. Huang, H. Zhang, Angew. Chem. 2015, 54, 3653; b) H.-S. Tsai, S.-W. Wang, C.-H. Hsiao, C.-W. Chen, H. Ouyang, Y.-L. Chueh, H.-C. Kuo, J.-H. Liang, Chem. Mater. 2016, 28, 425.

[8] G. Yanalak, F. Doganay, Z. Eroglu, H. Kucukkececi, E. Aslan, M. Ozmen, S. Z. Bas, O. Metin, I. Hatay Patir, Appl. Surf. Sci. 2021, 557, 149755.

[9] M. Zhu, S. Kim, L. Mao, M. Fujitsuka, J. Zhang, X. Wang, T. Majima, J. Am. Chem. Soc. 2017, 139, 13234.

[10]D. A. Reddy, E. H. Kim, M. Gopannagari, Y. Kim, D. P. Kumar, T. K. Kim, Appl. Catal. B: Environ. 2019, 241, 491.

[11]M. Zhu, Y. Osakada, S. Kim, M. Fujitsuka, T. Majima, Appl. Catal. B: Environ. $\mathbf{2 0 1 7}, 217,285$.

[12]S. Xu, S. Gong, H. Jiang, P. Shi, J. Fan, Q. Xu, Y. Min, Appl. Catal. B: Environ. 2020, 267, 118661 .

[13]Y.-J. Yuan, Z.-K. Shen, S. Song, J. Guan, L. Bao, L. Pei, Y. Su, S. Wu, W. Bai, Z.-T. Yu, Z. Ji, Z. Zou, ACS Catal. 2019, 9, 7801. 
[14]L. Kong, Y. Ji, Z. Dang, J. Yan, P. Li, Y. Li, S. F. Liu, Adv. Funct. Mater. 2018, 28,1800668 .

[15]O. Elbanna, M. Zhu, M. Fujitsuka, T. Majima, ACS Catal. 2019, 9, 3618.

[16]M. Zhu, X. Cai, M. Fujitsuka, J. Zhang, T. Majima, Angew. Chem. Int. Ed. 2017, $56,2064$. 